\title{
Issues with Diabetic Foot Ulceration
}

\author{
*Abdulrazzaq Alobaid \\ Kuwait Institute of Medical Specialization, Kuwait
}

Submission: March 06, 2017; Published: March 10, 2017

*Corresponding author: Abdulrazzaq Alobaid, Kuwait Institute of Medical Specialization, P.O.Box: 1160 Surra 45712 Kuwait, Tel: (+965) 99610013; Email: dralobaid@hotmail.com

Background

Diabetic foot problems, such as ulcerations, infections, and gangrene, are the most common cause of hospitalization among diabetic patients. More than 80,000 amputations are performed each year on diabetic patients in the United States, and $\sim 50 \%$ of the people with amputations will develop ulcerations and infections in the contralateral limb within 18 months. An alarming 58\% will have a contralateral amputation 3-5 years after the first amputation. In addition, the 3-year mortality after a first amputation has been estimated as high as 20$50 \%$, and these numbers have not changed much in the past 30 years, despite huge advances in the medical and surgical treatment of patients with diabetes.

Keywords: Diabetes; Ulcer; Prevention; Issues

\section{Discussion}

The majority of foot ulcers appear to result from minor trauma in the presence of sensory neuropathy. This best describes the critical triad most commonly seen in patients with diabetic foot ulcers: peripheral sensory neuropathy, deformity, and trauma. All three of these risk factors are present in 65\% of diabetic foot ulcers. Calluses, edema, and peripheral vascular disease have also been identified as etiological factors in the development of diabetic foot ulcers [1].

The risk of lower extremity amputation is 15 to 46 times higher in diabetics than in persons who do not have diabetes mellitus. The vast majority of diabetic foot complications resulting in amputation begin with the formation of skin ulcers. Early detection and appropriate treatment of these ulcers may prevent up to 85 percent of amputations. Unfortunately, several studies have found that primary care physicians infrequently perform foot examinations in diabetic patients during routine office visits. The feet of hospitalized diabetics may also be inadequately evaluated [2].

A thorough evaluation of any ulcer is critical and should direct management. An adequate description of ulcer characteristics, such as size, depth, appearance, and location, also provides for the mapping of progress during treatment. The evaluation should determine the etiology of the ulcer and ascertain whether the lesion is neuropathic, ischemic, or neuro-ischemic. Failure to perceive the pressure of a 10 -g monofilament is a proven indicator of peripheral sensory neuropathy and loss of protective sensation. Classification of ulcerations can facilitate a logical approach to treatment and aid in the prediction of outcome. The most widely accepted classification system for diabetic foot ulcers and lesions is the Wagner ulcer classification system. The drawback of the Wagner classification system is that it does not specifically address two critically important parameters: ischemia and infection. The University of Texas diabetic wound classification system assesses the depth of ulcer penetration, the presence of wound infection, and the presence of clinical signs of lower-extremity ischemia. The University of Texas system is generally predictive of outcome, because wounds of increasing grade and stage are less likely to heal without revascularization or amputation [3]. Increasing stage, regardless of grade, is associated with increased risk of amputation and prolonged ulcer healing time. The UT system's inclusion of stage makes it a better predictor of outcome than Wagner's classification [4].

A history of previous ulceration is the highest risk factor for ulceration and demonstrates, for the first time, that the presence of plantar callus is highly predictive of subsequent ulceration. Careful history taking and examination of the foot to detect the presence of callus require no special training or equipment and callus should be recognized as a 'high risk' factor for foot ulceration [5].

When assessing the economic effects of diabetic foot disease, it is important to remember that rates of recurrence of 
foot ulcers are very high, being greater than $50 \%$ after 3 years. Costing should therefore include not only the immediate ulcer episode, but also social services, home care, and subsequent ulcer episodes. A broader view of total resource use should include some estimate of quality of life and the final outcome. An integrated care approach with regular screening and education of patients at risk requires low expenditure and has the potential to reduce the cost of health care [6].

Pham et al. have shown that the combination of clinical examination and Semmes-Weinstein monofilaments testing is the most sensitive method for identifying the patient at risk for foot ulceration. Vibration perception threshold measurements are also helpful and can be used as an alternative. Finally, foot pressure measurements offer a substantially higher specificity and can be used as a post screening test in conjunction with providing appropriate footwear [7].

Analyses of economic impact have shown (1) the majority of costs occur in the inpatient setting, (2) a lack of financial benefit when comparing primary amputation with an aggressive approach to limb salvaging including vascular reconstruction, and (3) private insurance provides greater reimbursement for inpatient care than does Medicare [8].

If not treated promptly and appropriately, diabetic foot infections can become incurable or even lead to septic gangrene, which may require foot amputation. Staphylococcus aureus is the most common isolate in these infections; the increasing incidence of methicillin-resistant S. aureus over the past two decades has further complicated antibiotic treatment. Most patients must first be medically stabilized and any metabolic aberrations should be addressed. Antibiotic therapy is not required for uninfected wounds but should be carefully selected for all infected lesions. Surgical intervention is usually required in cases of retained purulence or advancing infection despite optimal medical therapy. Possible additional indications for surgical procedures include incision and drainage of an abscess, debridement of necrotic material, removal of any foreign bodies, arterial revascularization and, when needed, amputation. Most foot ulcers occur on the plantar surface of the foot, thus requiring a plantar incision for any drainage procedure [9].

Foot problems are significantly associated with mental health symptoms in diabetic patients and caregivers. This may affect treatment in the foot clinic, outcome, and quality of life [10]. Simson et al. [11] concluded that at the beginning of the treatment $18 \%$ of the inpatients suffered from severe depressive symptoms, and $16.2 \%$ suffered from moderate depressive symptoms. $16.4 \%$ of the patients suffered from severe anxiety, and $24.7 \%$ suffered from moderate anxiety (HADS). The prevalence rate of the type D pattern was $33.0 \%$. The extent of anxiety and depression was not, as had been anticipated, associated with the severity of the physical symptoms. Although the diabetic foot syndrome improved significantly in most of the patients, the extent of depressive symptoms, anxiety and diabetes-related problems remained almost the same [11].

Diabetic patients with a healed foot ulcer had a higher health-related quality of life than patients with a persisting ulcer. Health-related quality of life declined progressively when the ulcer did not heal. A diabetic foot ulcer appeared to be a large emotional burden on the patients' caregivers, as well [12].

\section{Conclusion}

Screening allows the clinician to assign the patient to a risk category that dictates both the type and frequency of foot interventions needed. Effective interventions include patient (and clinician) education.

Possibly effective interventions include optimizing glycemic control, smoking cessation, intensive podiatric care, and debridement of calluses. The value of prescription footwear for ulcer prevention is unclear. In selected cases, evaluation for surgical procedures maybe indicated. Each of these interventions, when used appropriately, may reduce the risk of foot ulceration and its devastating consequences [13].

Aggressive treatment of infections, correction of vascular occlusive disease, adequate wound care, and appropriate pressure mitigation are essential steps in the treatment protocol. With the implementation of good prevention and treatment programs, a significant reduction of lower extremity complications is well within reach [14].

\section{References}

1. Ingrid Kruse, Steven Edelman (2006) Evaluation and Treatment of Diabetic Foot Ulcers. Clinical Diabetes 24(2): 91-93.

2. David G Armstrong, Lawrence A Lavery (1998) Diabetic Foot Ulcers: Prevention, Diagnosis and Classification. Am Fam Physician 57(6): 1325-1332.

3. Robert G Frykberg (2002) Diabetic Foot Ulcers: Pathogenesis and Management. Am Fam Physician 66(9): 1655-1663.

4. Samson O Oyibo, Edward B. Jude, Ibrahim Tarawneh, Hienvu C Nguyen, Lawrence B Harkless, et al. (2001) A Comparison of Two Diabetic Foot Ulcer Classification Systems the Wagner and the University of Texas wound classification systems. Diabetes Care 24(1): 84-88.

5. Murray HJ, Young MJ, Hollis S, Boulton AJ (1996) The Association between Callus Formation, High Pressures and Neuropathy in Diabetic Foot Ulceration. Diabet Med 13: 979-982.

6. Boulton AJ, Vileikyte L, Ragnarson Tennvall G, Apelgvist J (2005) The global burden of diabetic foot disease. The Lancet 366(9498): 17191724.

7. Pham H, Armstrong DG, Harvey C, Harkless LB, Giurini JM, et al. (2000) Screening techniques to identify people at high risk for diabetic foot ulceration: a prospective multicenter trial. Diabetes Care 23(5): 60611.

8. Gayle E Reiber, Benjamin A Lipsky, Gary W Gibbons (1998) The burden of diabetic foot ulcers. The American Journal of Surgery 176(2): $5 \mathrm{~S}-10 \mathrm{~S}$.

9. Armstrong DG, Lipsky BA (2004) Diabetic foot infections: stepwise medical and surgical management. Int Wound J 1(2): 123-32. 
10. Christopher Hoban, Jitender Sareen, Christine A Henriksen, Lorraine Kuzyk, John M Embil, et al. (2015) Mental health issues associated with foot complications of diabetes mellitus. Foot and Ankle Surgery 21(1 ): 49-55.

11. Simson U, Nawarotzky U, Porck W, Friese G, Schottenfeld Naor Y, et al. (2008) Depression, anxiety, quality of life and type D pattern among inpatients suffering from diabetic foot syndrome. Psychother Psychosom Med Psychol 58(2): 44-50.

12. Nabuurs Franssen MH, Huijberts MS, Nieuwenhuijzen Kruseman AC, Willems J, Schaper NC, et al. (2005) Health-related quality of life of diabetic footulcer patients and their caregivers. Diabetologia 48(9): 1906-10.

13. Singh N, Armstrong DG, Lipsky BA (2005) Preventing foot ulcers in patients with diabetes. JAMA 293(2): 217-28.

14. Stephanie C Wu, Vickie R Driver, James S Wrobel, David G Armstrong (2007) Foot ulcers in the diabetic patient, prevention and treatment. Vasc Health Risk Manag 3(1): 65-76.

\section{Your next submission with Juniper Publishers will reach you the below assets}

- Quality Editorial service

- Swift Peer Review

- Reprints availability

- E-prints Service

- Manuscript Podcast for convenient understanding

- Global attainment for your research

- Manuscript accessibility in different formats

( Pdf, E-pub, Full Text, Audio)

- Unceasing customer service

Track the below URL for one-step submission https://juniperpublishers.com/online-submission.php 